Social Influences in Recruitment: When is Word-of-Mouth Most Effective? Greet Van Hoye, Bert Weijters, Filip Lievens, and Sara Stockman Ghent University, Belgium

Accepted for publication in International Journal of Selection and Assessment

Greet Van Hoye, Department of Human Resource Management and Organizational Behavior, Ghent University, Belgium; Bert Weijters, Department of Personnel Management, Work and Organizational Psychology, Ghent University, Belgium; Filip Lievens, Department of Personnel Management, Work and Organizational Psychology, Ghent University, Belgium; Sara Stockman, Department of Human Resource Management and Organizational Behavior, Ghent University, Belgium.

This paper was presented at the $3^{\text {rd }}$ EAWOP Small Group Meeting of the European Network of Selection Researchers (ENESER), Ghent, Belgium (2014, August). We wish to thank Pieter François and the Flemish Public Employment Service for their help in collecting data.

Correspondence concerning this paper should be addressed to Greet Van Hoye, Department of Human Resource Management and Organizational Behavior, Ghent University, Henleykaai 84, 9000 Ghent, Belgium. Phone: +32-9-243-29-56, E-mail: greet.vanhoye@ ugent.be 


\begin{abstract}
We apply a policy-capturing design to examine the conditions under which word-of-mouth is most effective in recruitment. The effect of monetary incentives is compared to other key characteristics of word-of-mouth (the source, recipient, and message content) that might affect its impact on organizational attractiveness. In a first study, unemployed job seekers $(N=100)$ were less attracted when they knew a monetary incentive was offered to the source of positive wordof-mouth. Conversely, they were more attracted when word-of-mouth was provided by a more experienced source (employee) and by a stronger tie (friend). These findings were replicated in a second study among employed job seekers $(N=213)$. These results offer various implications for how recruiting organizations might make effective use of word-of-mouth.

Keywords: recruitment, employer branding, recruitment source, word-of-mouth, organizational attractiveness, incentive.
\end{abstract}




\section{Social Influences in Recruitment: When is Word-of-Mouth Most Effective?}

Due to the worldwide economic recession, job search has become an integral part of people's work life. At the same time, the "war for talent" continues as organizations struggle to strike a balance between keeping a lean workforce yet attracting the necessary talent to ensure organizational success and survival. As these evolutions warrant a thorough understanding of job search and recruitment, research within these domains has grown exponentially over the last years (Boswell, Zimmerman, \& Swider, 2012; Breaugh, 2013). Recent studies have moved the field forward by using marketing theories, metaphors, and constructs to further elucidate the job search and recruitment process (Collins \& Kanar, 2014).

One of the key factors that determine job seekers' attraction to organizations is the source through which they receive employment information (Breaugh, 2013). Job seekers learn about job openings through a wide array of sources such as advertising, job sites, and job fairs. In addition, job seekers often consult family, friends, and other people about jobs. Such interpersonal sources have become even more important given the omnipresence of online social media (Nikolaou, 2014). Applying an employer branding perspective to recruitment, some studies have begun to investigate the effects of word-of-mouth as a company-independent recruitment source (Collins \& Stevens, 2002). Together, these studies indicate that word-ofmouth can be an influential source of employment information affecting important job search and recruitment outcomes (for a review, see Van Hoye, 2014).

In light of these developments, organizations seek to utilize the power of word-of-mouth in recruitment and explore ways in which it might be stimulated most effectively. However, this is not straightforward given the independent and interpersonal nature of word-of-mouth. In addition, prior research has not been very informative about the conditions under which word-ofmouth is likely to be most influential. One of the strategies that companies apply consists of 
offering monetary incentives to employees for spreading vacancies and recommending their employer to people they know. A recent US compensation survey revealed that $63 \%$ of participating companies had installed an employee referral bonus program (WorldatWork, $2014)^{1}$. Surprisingly, despite their widespread use, almost no research has investigated the effectiveness of these reward programs (Van Hoye, 2013). A concern might be that rewarding people to spread positive word-of-mouth undermines its impact as a recruitment source, as it might no longer be perceived as independent from the organization when potential applicants are aware of the monetary incentive.

The current study applies a policy-capturing design to investigate whether providing monetary incentives can decrease the impact of word-of-mouth on organizational attractiveness for potential applicants. In addition, the effect of incentives is compared to other key word-ofmouth characteristics, namely its source, recipient, and message content. Our hypotheses are tested in two different samples of actual job seekers, thereby taking possible differences between the unemployed and employed job seeker populations into account (Boswell et al, 2012).

On a theoretical level, this study goes beyond prior research that primarily demonstrated an overall positive effect of word-of-mouth on organizational attraction by systematically examining the specific conditions under which word-of-mouth is likely to be most influential as a recruitment source. At a practical level, this study offers implications for organizations that aim to more effectively incorporate word-of-mouth into their recruitment efforts.

\footnotetext{
${ }^{1}$ Given that we could not locate such figures for the Belgian labor market (where our research was conducted), we contacted all companies (46) who appeared on the Top 10 list of "Best Workplaces in Belgium" in the last five years (see http://www.greatplacetowork.be/best-workplaces/best-workplaces-in-belgie). Of the 34 companies who replied (74\% response rate), 26 indicated that they offered employees a monetary reward for positive referrals. The prevalence of employee referral bonus programs in this group thus seemed high (76\%), and this was the case for both companies under and over 500 employees (respectively $87 \%$ and 68\%).
} 


\section{Word-of-Mouth as a Recruitment Source}

Word-of-mouth as a recruitment source is defined as an interpersonal communication about an organization as an employer or about specific jobs, that is not under the direct control of the organization (Van Hoye \& Lievens, 2009). Contrary to company-controlled sources such as advertising, word-of-mouth is generated by people who are perceived to have no commercial self-interest in promoting the organization (Matos \& Rossi, 2008). Therefore, information from recruiters is not considered to be word-of-mouth (Cable, Aiman-Smith, Mulvey, \& Edwards, 2000). In addition, given its independent nature, word-of-mouth can contain positive as well as negative information, both in varying amounts (Van Hoye \& Lievens, 2007b). For instance, a job seeker might be exposed to no word-of-mouth at all, to both positive and negative word-of-mouth (in varying levels), or to only positive or negative word-of-mouth. Along these lines, Van Hoye and Lievens (2009) found that receiving positive word-of-mouth and receiving negative word-ofmouth were only moderately correlated $(r=.38, p<.01)$ and showed differential relationships with determinants and outcomes. In this study, we focus on positive word-of-mouth because this is the type of recruitment information that organizations aim to stimulate. It does not seem likely that an organization would award incentives for spreading negative word-of-mouth to potential applicants. In addition, as we will discuss below, prior research has consistently found a significant impact of positive word-of-mouth on organizational attraction, while the results for negative word-of-mouth have been mixed (Van Hoye, 2014).

Whereas the powerful impact of word-of-mouth on consumer attitudes and behavior has long been established in the marketing literature (Matos \& Rossi, 2008), recruitment studies have only recently begun to investigate word-of-mouth as a source of employment information (Collins \& Stevens, 2002; Jaidi, Van Hooft, \& Arends, 2011; Van Hoye, 2012; Van Hoye \& Lievens, 2005, 2007a, 2007b, 2009). The results of these studies can be summarized as follows. 
First, positive word-of-mouth has been found to affect a wide variety of attraction outcomes, including organizational image, organizational attractiveness, application intentions, and application decisions. Hence, word-of-mouth seems to be an influential source of positive employment information in various stages of the recruitment process, in which more immediate attraction outcomes mediate the effect on more distant outcomes (Jaidi et al., 2011). These effects of positive word-of-mouth appear to be robust and generalizable because they have been observed across different samples, settings, jobs, organizations, and countries.

Second, taking the effects of other recruitment sources such as recruitment advertising, web-based recruitment, recruitment events, publicity, and sponsorship into account, positive word-of-mouth seems to explain unique and incremental variance in organizational attraction (Van Hoye \& Lievens, 2009). In addition, the effects of word-of-mouth appear to be larger than most of these other recruitment sources (Collins \& Stevens, 2002).

Third, the effects of word-of-mouth seem to be at least partly due to its credibility as an independent and personal source of employment information (Van Hoye, 2012). More credible sources of information are generally more persuasive in both changing attitudes and gaining behavioral compliance (Pornpitakpan, 2004). Compared to company-controlled sources, word-ofmouth is likely to be perceived as providing more credible information because it does not have the explicit purpose to promote the organization (Van Hoye \& Lievens, 2005). In addition, job seekers tend to perceive information obtained through direct personal communication as more credible than indirect impersonal information (Cable et al., 2000).

\section{Determinants of the Impact of Word-of-Mouth}

Despite the overall favorable impact of positive word-of-mouth on organizational attraction, some initial evidence suggests that the size of its effect might be influenced by its specific context and characteristics (Van Hoye \& Lievens, 2007b). As we highlighted above, 
word-of-mouth is conceptualized as a dyadic communication in which a company-independent source sends an employment-related message that is received by a recipient potentially interested in working for the organization (Gilly, Graham, Wolfinbarger, \& Yale, 1998). This implies that the impact of word-of-mouth might be affected by the characteristics of the source, the recipient, as well as the message (Bansal \& Voyer, 2000).

\section{Source Characteristics}

A first key characteristic of the source is the motive for spreading positive word-ofmouth. Some organizations offer incentives (mostly monetary bonuses) to their employees for recommending their employer to others (WorldatWork, 2014). Other organizations even extend this practice to non-employees (e.g., customers) and offer rewards for spreading relevant vacancies to family and friends (sometimes called "refer-a-friend" programs). Providing some preliminary evidence for the effectiveness of these recruitment practices, Van Hoye (2013) found that employees in an organization that provides monetary incentives spread more positive wordof-mouth about their employer than employees in a comparable organization without incentives. However, other motives such as job satisfaction and the desire to help job seekers find good fitting jobs were more predictive of employees' word-of-mouth behavior than these rewards. In addition, rewarding sources for spreading positive word-of-mouth might lead recipients to perceive the source as having a self-interest in promoting the organization when they are aware of this incentive. Incentive-driven word-of-mouth would then no longer be perceived as entirely independent from the organization, which is likely to undermine its credibility. Given that its perceived credibility as an independent source of employment information is a main driver of the effect of word-of-mouth (Van Hoye, 2012), offering financial incentives for spreading word-ofmouth might reduce its impact. Along these lines, Van Hoye and Lievens (2007a) observed that testimonials of employees about their employer were less credible and influential when they were 
presented on the organization's own website than on an independent website, probably due to the higher perceived degree of organizational control.

Hypothesis 1. Recipients of positive word-of-mouth will be less attracted when they know a monetary incentive is offered to the source.

Another important attribute of the source is its expertise or the degree of knowledge and experience the source possesses with respect to the job or recruiting organization (Van Hoye \& Lievens, 2009). In a recruitment context, sources of word-of-mouth who work for the organization themselves are likely to be seen as possessing higher expertise than sources not working for the organization. Fisher, Ilgen, and Hoyer (1979) identified expertise as a major determinant of source credibility and found that potential applicants perceived job incumbents as more knowledgeable (i.e., being able to provide valuable and correct employment information) sources of employment information than recruiters. In addition, information from job incumbents had a more positive effect on organizational attractiveness than recruiter information. This implies that positive word-of-mouth provided by more experienced sources might be perceived as more credible and thus may have a larger impact on organizational attractiveness.

\section{Hypothesis 2. Recipients of positive word-of-mouth will be more attracted when the} source is an employee of the organization.

\section{Recipient Characteristics}

In addition to the source, characteristics of the recipient are also likely to play a part in how communicated information is processed and weighted (Gilly et al., 1998). In particular, some individuals are thought to be more susceptible to interpersonal information (Van Hoye \& Lievens, 2007b). Along these lines, the literature on gender differences suggests that compared to men, women seem to place a greater emphasis on interpersonal relationships, communicate more often, and react more to information provided by others (Brannon, 2008). Research in a 
marketing context reveals that women describe themselves as being more receptive to word-ofmouth information (Kempf \& Palan, 2006) and are more likely to change their attitudes as a result of online word-of-mouth than men (Garbarinoa \& Strahilevitz, 2004). Therefore, we expect that positive word-of-mouth will exert more influence on the organizational attractiveness perceptions of women than of men.

Hypothesis 3. Women will be more attracted than men when receiving positive word-ofmouth.

In addition, relying too heavily on word-of-mouth in recruitment might contribute to preserving existing imbalances in organizations (e.g., in terms of gender, ethnicity, or socioeconomic status) because people are typically attracted to similar others and social networks tend to be rather homogeneous (McPherson, Smith-Lovin, \& Cook, 2001). Therefore, we also manipulate source gender and explore the effects of gender similarity between the recipient and source of word-of-mouth.

Hypothesis 4. Recipients of positive word-of-mouth will be more attracted when the source is of the same gender.

\section{Source-Recipient Relationship}

Given the dyadic nature of word-of-mouth, its impact is likely to be determined not only by the separate characteristics of its recipient and its source, but also by their mutual relationship (Gilly et al., 1998). In this respect, tie strength refers to the closeness of the social relationship between the recipient and the source of word-of-mouth information. Friends and family are examples of strong ties, whereas acquaintances are considered to be weak ties. Marketing research suggests that stronger ties have a greater influence on consumers' attraction to products (Bansal \& Voyer, 2000). In a recruitment context, Van Hoye and Lievens (2007b) found that word-of-mouth from a friend was perceived as more credible and had a more positive effect on 
organizational attractiveness than word-of-mouth from an acquaintance. We aim to replicate this finding in a sample of actual job seekers (rather than students), while controlling for other key characteristics of the source, recipient, and message of word-of-mouth.

Hypothesis 5. Recipients of positive word-of-mouth will be more attracted when the source is a friend rather than an acquaintance.

\section{Message Characteristics}

In addition to the source and the recipient, the communicated message is a third major component of word-of-mouth that is likely to influence its impact (Matos \& Rossi, 2008). With respect to the valence of the provided information, prior research found that positive word-ofmouth is associated with higher organizational attractiveness than negative word-of-mouth (Van Hoye \& Lievens, 2007b). Given that we focus on positive word-of-mouth in the current study, we further scrutinize the type of job and organizational attributes being communicated. In this context, Lievens and Highhouse (2003) distinguished between instrumental and symbolic employment information. Instrumental information describes the job or organization in objective, concrete, and factual terms (e.g., "The company pays high wages") whereas symbolic employment information uses subjective, abstract, and intangible terms (e.g., "The company is a highly regarded employer").

Even though both types of information contribute significantly to employer attraction, organizations are better differentiated from each other on the basis of symbolic job and organizational information (Lievens \& Highhouse, 2003). In addition, people are attracted to these symbolic company traits because they enable them to establish and communicate their identity and to gain social approval (Highhouse, Thornbury, \& Little, 2007). So, what other people are saying about a company seems to be especially relevant for symbolic company 
characteristics (Cable et al., 2000). All of this suggests that word-of-mouth might have a larger impact on attraction when symbolic rather than instrumental information is provided.

Hypothesis 6. Recipients of positive word-of-mouth will be more attracted when the message contains symbolic rather than instrumental information.

\section{Study 1}

\section{Method}

Participants. Addressing criticisms of using student samples in recruitment research (Breaugh, 2013), we tested our hypotheses among actual job seekers. Our sample consisted of 100 unemployed job seekers who were asked to participate in this study during their visit to a local office of the Flemish Public Employment Service in Belgium. Given that gender of the word-of-mouth recipient was a between-subjects factor in our design, we purposively approached individuals so that 50 men and 50 women were included in our final sample. Age varied from 17 to 57 years $(M=30.03$ years, $S D=9.66)$. With respect to education, $10 \%$ obtained a primary school degree, $67 \%$ a high school degree, and $23 \%$ a college degree.

Design and procedure. A research assistant visited the public employment agency and approached potential participants personally and individually. The purpose of the study was described broadly as "examining perceptions of organizations as employers". It was stressed (1) that participation was voluntary and anonymous, (2) that answers would be used for research purposes only, and (3) that participants should answer honestly based on their own opinion, as there were no right or wrong answers. If job seekers agreed to participate, they could complete the paper-and-pencil survey in a separate quiet room of the employment agency. The research assistant remained present to answer any questions or comments and to supervise survey administration. Given the considerable length of the questionnaire, participants were offered a beverage and a cookie to increase their comfort. Completing the survey took about 35 minutes. 
Applying a policy-capturing design, participants were asked to evaluate a series of wordof-mouth scenarios that were systematically varied with respect to incentive (no monetary reward versus monetary reward), source expertise (non-employee versus employee), source gender (male versus female), tie strength (acquaintance versus friend), and message content (instrumental versus symbolic). These within-subjects variables were fully crossed, resulting in a $2 \times 2 \times 2 \times 2$ $\times 2$ factorial design with 32 different scenarios, in line with recommendations regarding the optimal number of cues, values, and scenarios in a policy-capturing design (Aguinis \& Bradley, 2014). Recipient gender (i.e., gender of the participant) was a between-subjects factor in our design. To adequately test its effect and explore possible gender similarity effects, we controlled for source gender and the interaction between source and recipient gender. To familiarize respondents with the task and account for start-up effects, a practice scenario was provided at the start of the survey. In addition, a duplicate scenario was added at the end, to allow estimating judgment reliability (Aguinis \& Bradley, 2014). This resulted in a total of 34 scenarios to be evaluated. There were four different versions of the questionnaire containing a different randomized order of the scenarios. Five respondents who rated all scenarios equally were excluded from further analyses (Aguinis \& Bradley, 2014).

Participants were instructed to imagine that they were currently looking for a job (similar to their own situation, enhancing the realism of the experimental task). After a visit to an employment agency, they supposedly check their email account and find a number of new messages in their inbox. Participants were asked to carefully read these (printed) emails and to answer two questions after each email assessing organizational attractiveness on a 5-point rating scale (Bretz \& Judge, 1998). The two items were "How interested would you be in obtaining an interview with this organization?" ( 1 = very uninterested, $5=$ very interested $)$ and "How likely is it that you will make further inquiries about this vacancy?" $(1=$ very unlikely, $5=$ very likely $)$. 
Given that the internal consistency of the scale's ratings was sufficiently high $(\alpha=.93)$, the average of the two items was used as the dependent variable. In addition, the ratings for the duplicate scenario at the end of the survey provide an indication of satisfactory reliability $(r=$ $.71, p<.01)$, suggesting that participants responded consistently to identical scenarios.

Stimulus materials. Materials consisted of 32 emails presenting positive word-of-mouth information about a fictitious company. These word-of-mouth scenarios resulted from the combination of the two levels of each of the five independent variables in our study's design. Table 1 provides a description of the operationalization of each factor and a visual example of a stimulus is displayed in the Appendix (translated from Dutch to English).

In addition to choosing a sample of actual job seekers, a number of measures were taken to enhance the external validity of our materials (Aguinis \& Bradley, 2014). First, the word-ofmouth scenarios were presented in a realistic format as print-screens of emails with an Outlook layout. Second, to enhance realism and respondent task variety, each scenario used a different fictitious company name and a different first name of the sender (in keeping with the intended source gender). Finally, some general information about the company and job vacancy was provided that was kept constant across conditions, to provide contextualization and make the word-of-mouth scenario more believable (see example in Appendix).

We conducted a pilot study to test the internal validity of our manipulations in a sample of 11 graduate students ( 5 women, 6 men). They were instructed to imagine that they were looking for a job and received two emails regarding job vacancies. They were asked to carefully read each (printed) email and answer a number of questions relating to the intended dimensions (see note to Table 1 for questions and rating scales). The two emails covered all factor levels (i.e., the first stimulus corresponded to a word-of-mouth situation with no incentive, low source expertise, a male source, strong tie, and symbolic message content; the second stimulus represented the 
opposite level of each factor). As shown in Table 1, four paired-samples $t$-tests indicated that the operationalizations of incentive, source expertise, tie strength, and message content worked as intended. In addition, all participants correctly identified source gender. Finally, participants were asked to categorize 50 first names as either male or female. Only names that were correctly classified by all participants were used to operationalize source gender in the main study.

\section{Results}

The intraclass correlation for organizational attractiveness was .27, so a multilevel modeling approach was required to obtain unbiased estimates of the parameters and their standard errors. Multilevel modeling takes into account that measurements are repeated within respondents and are therefore not independent of one another. In particular, data were analyzed using the TWOLEVEL procedure in Mplus 7.11. We estimated a model with a random intercept and dummy variables that captured incentive, source expertise, source gender, tie strength, and message content at the within-level, as well as recipient gender at the between-level. The withinlevel explained variance $\left(R^{2}\right)$ was $21.6 \%(p<.001)$, whereas the between-level explained variance (with recipient gender as the sole explanatory variable) was $0.0 \%(p=.953)$. A preliminary analysis showed that the cross-level interaction effect of recipient gender at the between-level and source gender at the within-level (i.e., gender similarity) was close to zero and not statistically significant, so this effect was not included in the reported model for reasons of parsimony and ease of interpretation.

The parameter estimates are reported in Table 2 and use the STDY scaling in Mplus; that is, the coefficients express the expected change in standard deviations of the dependent variable when the independent variable changes from zero to one. The independent variables are orthogonal and are all coded as dummy variables, so the coefficients are directly comparable as they indicate the relative impact of the related independent variable. In order of importance, the 
results showed a negative impact of incentive, a positive impact of tie strength and of source expertise, but no statistically significant effect for message content, source gender, or recipient gender. In addition, exploratory analyses indicated that none of the interactions between the independent variables were significant (tested at $p<.01$ to decrease chance capitalization).

To further interpret the observed effects, Figure 1 shows the expected (i.e., model implied) organizational attractiveness ratings for alternative word-of-mouth types defined by their incentive, source expertise, and tie strength levels. Organizational attractiveness was highest when word-of-mouth was not rewarded with an incentive and was provided by a friend who works for the organization. Organizational attractiveness was lowest when an incentive was offered for spreading positive word-of-mouth and it was provided by an acquaintance who does not work for the organization.

These results suggest that potential applicants were less attracted when they knew a monetary incentive was offered to the source of positive word-of-mouth, consistent with Hypothesis 1. In support of Hypothesis 2, organizational attractiveness was higher when the source was an employee of the organization. Women were not more attracted after receiving positive word-of-mouth than men, failing to support Hypothesis 3. In addition, with respect to Hypothesis 4, we did not find evidence for an effect of gender similarity between source and recipient. In support of Hypothesis 5, positive word-of-mouth led to higher organizational attractiveness when the source was a strong tie rather than a weak tie. Hypothesis 6 was not supported, as organizational attractiveness was not significantly different for receiving symbolic versus instrumental word-of-mouth information.

To test the robustness and generalizability of our findings, we conducted a second study examining our hypotheses in a sample of employed job seekers. Prior research found that the antecedents, processes, and outcomes of job search can be affected by the specific job search 
context and notable differences have been observed between unemployed and employed job seeker populations (Boswell et al., 2012).

\section{Study 2}

\section{Method}

Participants. The data for Study 2 were collected at the end of an omnibus online survey consisting of several sections related to other studies (total $N=740$ ). The survey was run among the Dutch online panel of a global data provider, using quota for age (from 20 to 50 years) and gender (50/50). The section of the questionnaire related to word-of-mouth was presented only to respondents who passed the following filters: (1) an instructed response item ("Do not select a response option for this question, but proceed to the next page (this is an attention check)."); (2) a filter to exclude non-job seekers ("What is the chance that you will look for (another) job in the coming year? No chance, a very small chance, a small chance, a reasonable chance, a big chance, a very big chance"; respondents who indicated "no chance" were not included in the current study); (3) a filter to identify employed people (i.e., we selected only respondents who were working part-time or full-time at the time of data collection). The resulting sample $(N=$ 213) had an average age of 36.62 years $(S D=8.36)$ and $42.9 \%$ were women. With respect to education, $2 \%$ obtained a primary school degree, $38 \%$ a high school degree, and $60 \%$ a college degree. Concerning employment status, $83.8 \%$ were working full-time and $16.2 \%$ part-time.

Design and procedure. The same word-of-mouth scenarios developed for Study 1 were used as stimulus materials in Study 2. However, given that no interactions between the independent variables were observed in Study 1 and that we wanted to reduce the time necessary to complete the survey, Study 2 no longer applies a fully crossed factorial design. Focusing on the three characteristics of word-of-mouth that showed an effect in Study 1, the within-subjects variables incentive (no monetary reward versus monetary reward), source expertise (non- 
employee versus employee), and tie strength (acquaintance versus friend) were fully crossed, resulting in a $2 \times 2 \times 2$ design with 8 different scenarios per respondent, presented in random order. Within these 8 presented stimuli, the levels of the other two within-subjects variables source gender (male versus female) and message content (instrumental versus symbolic) - were randomly chosen. Thus, for each respondent and each stimulus, one of the four alternative versions available from Study 1 (due to the variation in source gender and message content) was randomly selected for presentation. Note, however, that this approach still allowed us to investigate the effects of these two factors. Recipient gender was a between-subjects factor.

Participants were instructed to imagine that they were currently looking for a job. After a visit to an employment agency, they supposedly check their email account and find a number of new messages in their inbox. Participants were asked to carefully read each email and to assess organizational attractiveness ("How likely is it that you will make further inquiries about this vacancy?" on a scale ranging from $0=$ very unlikely to $10=$ very likely, using a visual rating scale with a circular gauge, available as a standard format in Qualtrics).

To familiarize respondents with the task, to let them calibrate their scale use, and for reasons of validation, all respondents first rated two stimuli that were the same for all respondents and duplicated two of the actual experimental stimuli (Aguinis \& Bradley, 2014). The ratings of these two warm-up emails show a correlation of .71 and .72 with their duplicate stimuli, thus indicating satisfactory reliability. Outliers for whom the discrepancy between duplicate stimuli was larger than 6 scale points (three respondents) were not included in further analyses.

\section{Results}

We followed the same analytic approach as used in Study 1. The cross-level interaction effect of source and recipient gender was not significant, so it was not included in the reported model. The parameter estimates in Table 2 indicate a negative impact of incentive and a positive 
impact of tie strength, source expertise, and symbolic message content. Exploratory analyses indicated that none of the interactions between the independent variables were significant. Figure 2 displays the expected mean scores of organizational attractiveness as a function of the four significant word-of-mouth characteristics. Organizational attractiveness was highest when wordof-mouth was not rewarded with an incentive, was provided by a friend who works for the organization, and contained symbolic information.

These results are largely similar to the results of Study 1, providing further support for incentive (Hypothesis 1), source expertise (Hypothesis 2), and tie strength (Hypothesis 5) as determinants of the impact of positive word-of-mouth on organizational attractiveness. In addition, we did not find evidence for any gender or gender similarity effects (Hypothesis 3 and Hypothesis 4). However, in Study 2, we did find some support for Hypothesis 6, as positive word-of-mouth led to higher organizational attractiveness when the message contained symbolic rather than instrumental information.

\section{Discussion}

\section{Main Conclusions}

Positive word-of-mouth has a significant effect on organizational attraction, which is larger than most other sources of employment information (Collins \& Stevens, 2002). As this warrants a more thorough understanding of word-of-mouth in recruitment, the current study expands prior research by demonstrating that positive word-of-mouth can be more - or less influential, depending on the specific conditions under which it is provided. In line with the conceptualization of word-of-mouth as a dyadic communication, characteristics of its source, recipient, and message were examined as possible determinants of its impact.

First, we found that the impact of positive word-of-mouth on organizational attractiveness was substantially reduced when potential applicants were aware of a monetary incentive offered 
to the source. Knowledge of this incentive seems to have led recipients to perceive the source of word-of-mouth as having a self-interest in promoting the organization, diminishing its credibility and impact (Van Hoye \& Lievens, 2007a). These findings were observed for both unemployed and employed job seekers, attesting to their robustness. Research on the effectiveness of recruitment incentive practices is scarce. Some evidence suggests that intrinsic and prosocial motives might be more effective for stimulating employees' word-of-mouth behavior than rewards (Van Hoye, 2013). Our findings extend prior research, as they suggest that offering monetary incentives can have a negative unintended effect on the impact of word-of-mouth.

Second, we observed that positive word-of-mouth provided by employees - who are assumed to have a high level of expertise concerning the organization - led to significantly higher organizational attractiveness perceptions among both unemployed and employed job seekers than word-of-mouth spread by people who do not work for the organization. Given that higher source expertise has been associated with higher source credibility (Fisher et al., 1979), it seems that potential applicants attached more belief and value to word-of-mouth from more experienced sources. Whereas previous research has already found that sources with higher expertise, such as employees, are more likely to spread positive word-of-mouth information (Van Hoye \& Lievens, 2009), the present findings suggest that the word-of-mouth that they provide might also have a larger impact on organizational attraction. Together, this implies that employees represent an important target group for organizations aiming to stimulate positive word-of-mouth, even though monetary rewards might not be the best way to achieve this.

Third, we found that positive word-of-mouth led to higher organizational attractiveness when the relationship between the source and recipient was stronger. This finding is in line with prior research in a student sample (Van Hoye \& Lievens, 2007b), demonstrating its generalizability to populations of unemployed and employed job seekers (Boswell et al., 2012) 
and its robustness while controlling for other key characteristics of the source, recipient, and message content of word-of-mouth. These results suggest that family and friends are not only likely to spread more positive word-of-mouth (Van Hoye \& Lievens, 2009), but also that their word-of-mouth might have a larger impact on potential applicants than word-of-mouth provided by weak ties such as acquaintances.

Finally, we found some evidence that the content of the word-of-mouth message might affect its impact. Specifically, potential applicants were more attracted when symbolic rather than instrumental employment information was provided. This suggests that word-of-mouth might be particularly relevant for the social identity concerns associated with symbolic company traits (Highhouse et al., 2007). However, this effect was only observed for employed job seekers and not for unemployed job seekers. This is consistent with prior research indicating that symbolic employment information and its implications for social identity matter more for employed individuals (Lievens, Van Hoye, \& Anseel, 2007).

\section{Limitations}

This study has some limitations that need to be acknowledged. First, the generalizability of the results may be restricted by our experimental design. However, this experimental control enabled us to carefully manipulate the content of the word-of-mouth scenarios and to examine the causal effects of word-of-mouth characteristics on organizational attractiveness. Moreover, we included two different samples of actual job seekers and applied some differences to the design (e.g., factors not fully crossed) and procedure (e.g., online) of our second study. Future research is needed to determine the generalizability of our findings to the field.

Second, due to our within-subjects design, demand characteristics might have contributed to the observed variations in organizational attractiveness, although several precautions were taken to reduce their potential influence. The study's purpose was described broadly, participants 
were instructed to answer honestly and were reassured that there were no wrong answers, and participation was anonymous. In addition, to enhance task variety, each scenario used a different company and sender name. Moreover, even though credibility seems to be the main theoretical explanation for the observed effects (Van Hoye, 2012), we deliberately decided not to measure it to avoid priming respondents in this direction.

Finally, the largest effect was observed for offering a monetary incentive for spreading word-of-mouth. This might be partly explained by the operationalization of incentive as a forwarded email message which might have drawn more attention than other factors operationalized by a single sentence within the main email message. However, this operationalization was consistent with actual organizational practices aimed at stimulating wordof-mouth. Moreover, our operationalization of incentive was fairly conservative, as only $50 €$ was offered, in the form of a gift voucher. It might be that even stronger negative effects would be observed for larger amounts and for purely monetary bonuses.

\section{Directions for Future Research}

To further advance our understanding of word-of-mouth in recruitment, we suggest the following avenues for future research. First, some organizations are offering monetary incentives in an attempt to stimulate positive word-of-mouth, but up until now the effectiveness of this practice has not been supported by research. Future research might investigate whether particular types of incentives might be effective in increasing word-of-mouth without reducing its credibility and impact. Examples might be donations to charity, non-financial incentives, or incentives that do not benefit the source but the recipient of word-of-mouth (or both). Second, more research is needed to investigate other specific strategies that companies might apply to stimulate positive word-of-mouth, such as employer branding, corporate social responsibility, campus recruitment, internships or sponsorship. In addition to evaluating the effects of these 
practices on the frequency of word-of-mouth, possible unintended effects on the credibility and impact of word-of-mouth should also be taken into account. Third, organizations are not only interested in stimulating positive word-of-mouth, but may also want to reduce negative word-ofmouth or mitigate its effects. Given that prior research has largely focused on positive recruitment information, future research should examine how negative information affects organizational attractiveness and how it might best be addressed. Along these lines, Van Hoye and Lievens (2005) demonstrated that both positive word-of-mouth and recruitment advertising can be used to dampen the effects of negative publicity on applicant attraction.

\section{Practical Implications}

Spreading employment information through word-of-mouth is one of the most powerful means of recruitment communication (Collins \& Stevens, 2002; Van Hoye \& Lievens, 2009). As organizations have no direct control over word-of-mouth, some have tried to stimulate positive word-of-mouth by offering monetary incentives. However, our results suggest that this recruitment practice can possibly reduce the impact of word-of-mouth when potential applicants perceive the source as having a self-interest in promoting the organization. Thus, although more research is needed, caution is required in designing and implementing incentive programs and evaluations of program effectiveness should take the total costs and benefits into account, including the possible unintended effects on potential applicants.

Our results further suggest that positive word-of-mouth from employees can lead to higher organizational attractiveness. Therefore, organizations should look for ways to stimulate employees' word-of-mouth other than by offering rewards. Intrinsically motivating employees by increasing their job satisfaction seems to be key here, as research has found that more satisfied employees spread more positive and less negative word-of-mouth (Van Hoye, 2013). Moreover, enhancing employees' perceptions of employer image seems to be an effective means to increase 
their willingness to recommend their employer to others (Van Hoye, 2008). This illustrates the importance of internal employer branding in addition to external branding (Lievens et al., 2007), as organizations need to be an attractive employer not only for potential applicants, but also - and even most importantly - for their own employees. Furthermore, organizations might appeal to employees' prosocial motives for spreading word-of-mouth (Van Hoye, 2013), for instance by emphasizing how vacancies might be good career choices for their friends or family.

Finally, word-of-mouth from stronger ties such as friends might be more influential as well as more frequent. Therefore, employees might be especially encouraged to share company vacancies with strong ties, for instance through personal social networking websites such as Facebook. In addition, organizations might consider including potential applicants' friends and family in their recruitment and branding activities. For instance, potential applicants might be stimulated to discuss vacancies with their friends or to bring their family to recruitment events. 


\section{References}

Aguinis, H., \& Bradley, K. J. (2014). Best-practice recommendations for designing and implementing experimental vignette methodology studies. Organizational Research Methods, 17, 351-371.

Bansal, H. S., \& Voyer, P. A. (2000). Word-of-mouth processes within a services purchase decision context. Journal of Service Research, 3, 166-177.

Boswell, W. R., Zimmerman, R. D., \& Swider, B. W. (2012). Employee job search: Toward an understanding of search context and search objectives. Journal of Management, 38, 129163.

Brannon, L. (2008). Gender: Psychological perspectives ( $5^{\text {th }}$ ed.). Boston, MA: Allyn and Bacon. Breaugh, J. A. (2013). Employee recruitment. Annual Review of Psychology, 64, 389-416.

Bretz, R. D., \& Judge, T. A. (1998). Realistic job previews: A test of the adverse self-selection hypothesis. Journal of Applied Psychology, 83, 330-337.

Cable, D. M., Aiman-Smith, L., Mulvey, P. W., \& Edwards, J. R. (2000). The sources and accuracy of job applicants' beliefs about organizational culture. Academy of Management Journal, 43, 1076-1085.

Collins, C. J., \& Kanar, A. M. (2014). Employer brand equity and recruitment research. In K. Y. T. Yu \& D. M. Cable (Eds.), The Oxford Handbook of Recruitment (pp. 284-297). New York: Oxford University Press.

Collins, C. J., \& Stevens, C. K. (2002). The relationship between early recruitment-related activities and the application decisions of new labor-market entrants: A brand equity approach to recruitment. Journal of Applied Psychology, 87, 1121-1133.

Fisher, C. D., Ilgen, D. R., \& Hoyer, W. D. (1979). Source credibility, information favorability, and job offer acceptance. Academy of Management Journal, 22, 94-103. 
Garbarinoa, E., \& Strahilevitz, M. (2004). Gender differences in the perceived risk of buying online and the effects of receiving a site recommendation. Journal of Business Research, 57, $768-775$.

Gilly, M. C., Graham, J. L., Wolfinbarger, M. F., \& Yale, L. J. (1998). A dyadic study of interpersonal information search. Journal of the Academy of Marketing Science, 26, 83100.

Jaidi, Y., Van Hooft, E. A. J., \& Arends, L. R. (2011). Recruiting highly educated graduates: A study on the relationship between recruitment information sources, the theory of planned behavior, and actual job pursuit. Human Performance, 24, 135-157.

Highhouse, S., Thornbury, E. E., \& Little, I. S. (2007). Social-identity functions of attraction to organizations. Organizational Behavior and Human Decision Processes, 103, 134-146.

Kempf, D. S., \& Palan, K. M. (2006). The effects of gender and argument strength on the processing of word-of-mouth communication. Academy of Marketing Studies Journal, 10, $1-16$.

Lievens, F., \& Highhouse, S. (2003). The relation of instrumental and symbolic attributes to a company's attractiveness as an employer. Personnel Psychology, 56, 75-102.

Lievens, F., Van Hoye, G., \& Anseel, F. (2007). Organizational identity and employer image: Towards a unifying framework. British Journal of Management, 18, S45-S59.

Matos, C. A., \& Rossi, C. A. V. (2008). Word-of-mouth communications in marketing: A metaanalytic review of the antecedents and moderators. Journal of the Academy of Marketing Science, 36, 578-596.

McPherson, M., Smith-Lovin, L., \& Cook, J. M. (2001). Birds of a feather: Homophily in social networks. Annual Review of Sociology, 27, 415-444.

Nikolaou, I. (2014). Social networking web sites in job search and employee recruitment. 
International Journal of Selection and Assessment, 22, 179-189.

Pornpitakpan, C. (2004). The persuasiveness of source credibility: A critical review of five decades' evidence. Journal of Applied Social Psychology, 34, 243-281.

Van Hoye, G. (2012). Recruitment sources and organizational attraction: A field study of Belgian nurses. European Journal of Work and Organizational Psychology, 21, 376-391.

Van Hoye, G. (2013). Recruiting through employee referrals: An examination of employees' motives. Human Performance, 26, 451-464.

Van Hoye, G. (2014). Word of mouth as a recruitment source: An integrative model. In K. Y. T. Yu \& D. M. Cable (Eds.), The Oxford Handbook of Recruitment (pp. 251-268). New York: Oxford University Press.

Van Hoye, G., \& Lievens, F. (2005). Recruitment-related information sources and organizational attractiveness: Can something be done about negative publicity? International Journal of Selection and Assessment, 13, 179-187.

Van Hoye, G., \& Lievens, F. (2007a). Investigating web-based recruitment sources: Employee testimonials versus word-of-mouse. International Journal of Selection and Assessment, $15,372-382$.

Van Hoye, G., \& Lievens, F. (2007b). Social influences on organizational attractiveness: Investigating if and when word-of-mouth matters. Journal of Applied Social Psychology, 37, 2024-2047.

Van Hoye, G., \& Lievens, F. (2009). Tapping the grapevine: A closer look at word-of-mouth as a recruitment source. Journal of Applied Psychology, 94, 341-352.

WorldatWork (2014). Bonus programs and practices. Research report available from $\underline{\text { www. worldatwork.org/adimLink? } \mathrm{id}=75444}$ 
Table 1

Operationalization of Independent Variables and Results of Pilot Study

\begin{tabular}{|c|c|c|c|c|c|c|}
\hline Variable & Level & Operationalization & $M$ & $S D$ & $t$ & $p$ \\
\hline \multirow[t]{2}{*}{ Incentive } & No & No forwarded email message. & 1.82 & .98 & -10.00 & $<.001$ \\
\hline & Yes & $\begin{array}{l}\text { Below the main message, a forwarded email message is shown in } \\
\text { which the HR manager of the company promises a } 50 € \text { gift } \\
\text { voucher for anyone who gets someone else to apply. }\end{array}$ & 4.55 & .69 & & \\
\hline \multirow[t]{2}{*}{ Source expertise } & Low & $\begin{array}{l}\text { "I do not work for this company myself, but I got to know it last } \\
\text { week". }\end{array}$ & 2.55 & .82 & -2.62 & .026 \\
\hline & High & "I've been working for this company for a couple of years now". & 3.55 & .93 & & \\
\hline \multirow[t]{2}{*}{ Source gender } & Male & $\begin{array}{l}\text { The first name of the sender of the email is selected from a list of } \\
\text { male first names (e.g., Peter). }\end{array}$ & .00 & .00 & - & - \\
\hline & Female & $\begin{array}{l}\text { The first name of the sender of the email is selected from a list of } \\
\text { female first names (e.g., Caroline). }\end{array}$ & 1.00 & .00 & & \\
\hline \multirow[t]{2}{*}{ Tie strength } & Weak & $\begin{array}{l}\text { The introduction to the email states that "an acquaintance of your } \\
\text { neighbor sends you the following email". }\end{array}$ & 1.36 & .50 & -8.03 & $<.001$ \\
\hline & Strong & $\begin{array}{l}\text { The introduction to the email states that "a good friend of yours } \\
\text { sends you the following email". }\end{array}$ & 3.18 & .75 & & \\
\hline \multirow[t]{2}{*}{ Message content } & Instrumental & $\begin{array}{l}\text { "The company offers good facilities that guarantee employee } \\
\text { safety and yields a solid annual revenue". }\end{array}$ & 2.30 & .67 & -6.71 & $<.001$ \\
\hline & Symbolic & $\begin{array}{l}\text { "The company cares about the safety of its employees and is } \\
\text { known as a reliable employer". }\end{array}$ & 3.80 & .42 & & \\
\hline
\end{tabular}

Note. Questions of the pilot study were respectively: "Do you think [sender name] is sending this email on [his/her] own accord or because [he/she] can earn a reward?" (1=entirely on own accord, 5=entirely for the reward), "Does [sender name] possess low or high expertise concerning the company?" $(1=v e r y$ low, $5=$ very high $)$, "What gender is the sender of this email?" ( $0=$ male, $1=$ female $)$, "How would you describe your relationship with [sender name]?" (1=very weak, $5=$ very strong), and "TThe company offers good facilities that guarantee employee safety and yields a solid annual revenue/The company cares about the safety of its employees and is known as a reliable employer]. How objective or subjective would you categorize this information?” (1=very objective, 5=very subjective).

With respect to source gender, all names were correctly classified. 


\section{Table 2}

Parameter Estimates for the Two-Level Regression of Organizational Attractiveness

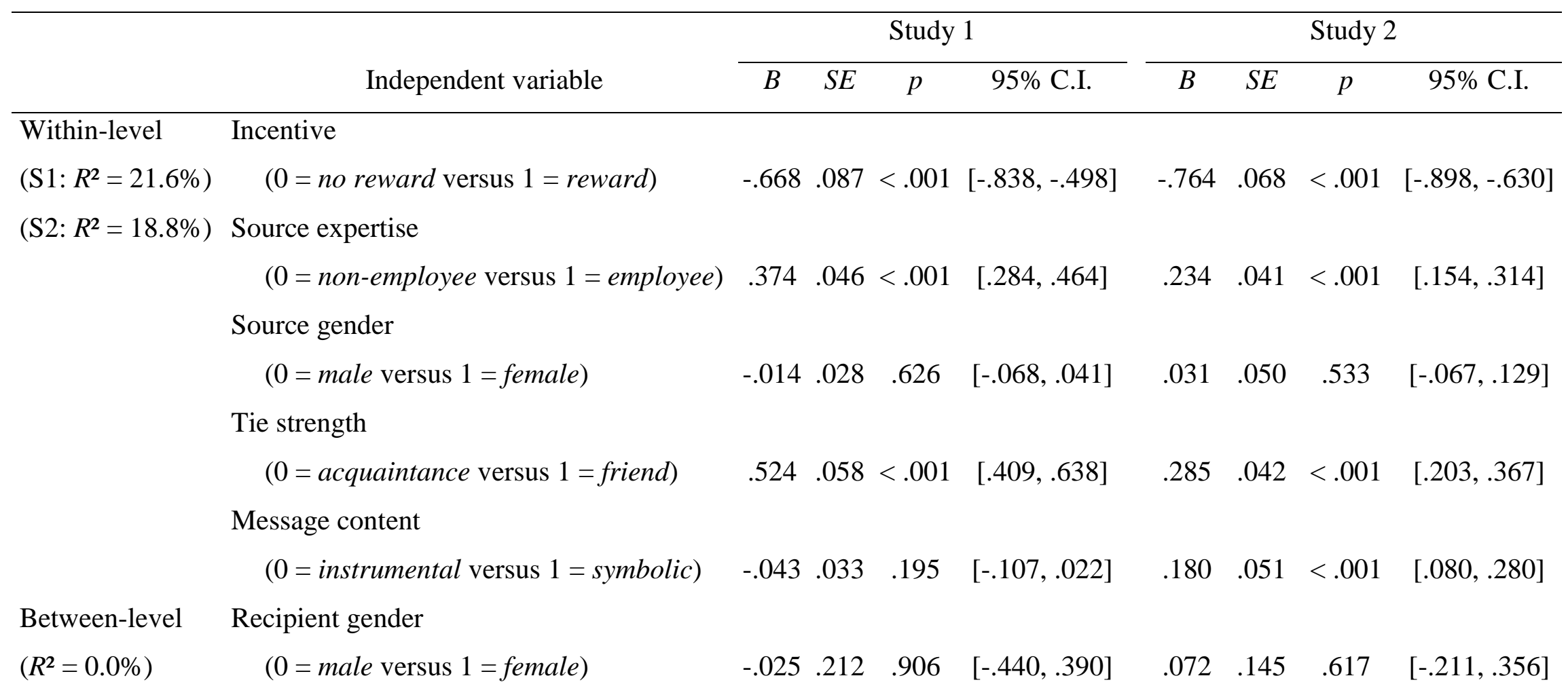

Note. S1=Study 1; S2= Study 2. Coefficients express the expected change in standard deviations of the dependent variable when the independent variable changes from zero to one (i.e., STDY standardization). The independent variables are all coded as dummy variables, so the coefficients are directly comparable as they indicate the relative impact of the related independent variable. 


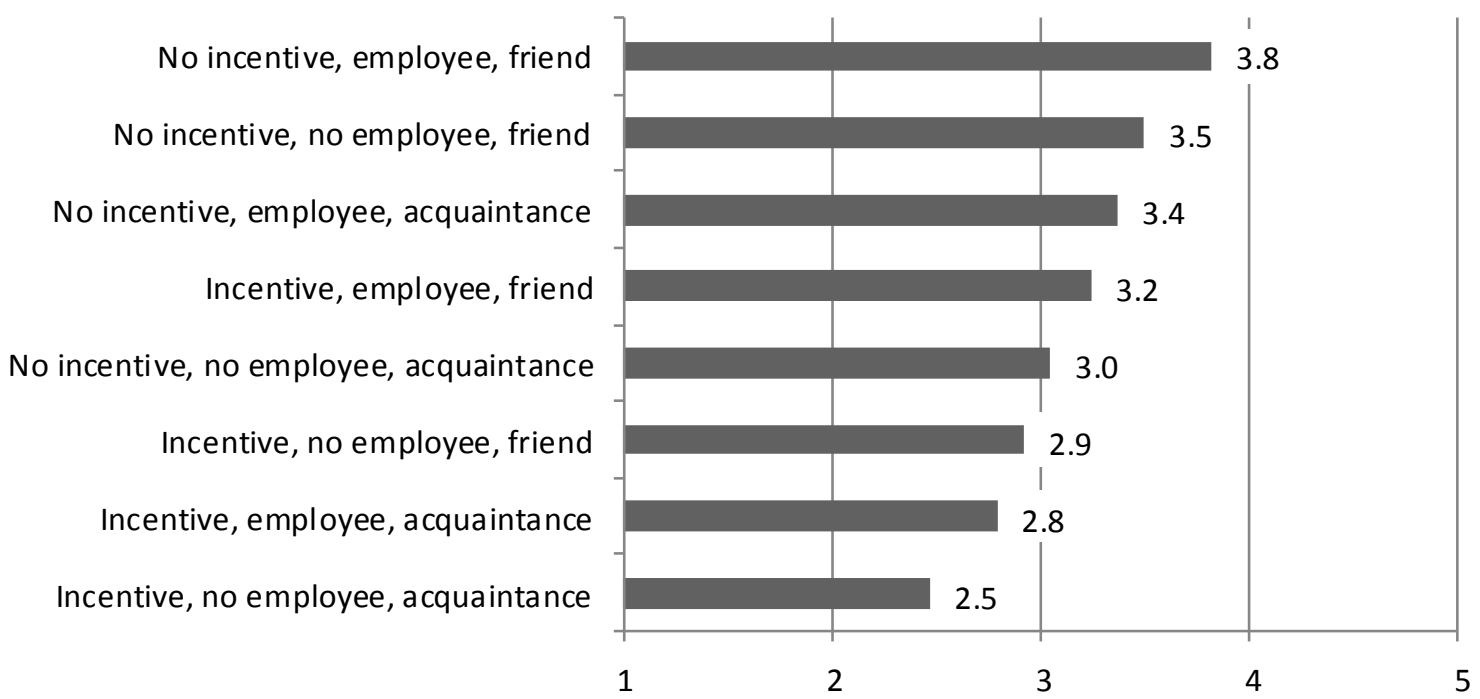

Expected organizational attractiveness

Figure 1. Expected organizational attractiveness as a function of significant word-of-mouth characteristics, in descending order (Study 1).

No incentive, employee, friend, symbolic No incentive, employee, friend, instrumental No incentive, no employee, friend, symbolic No incentive, employee, acquaintance, symbolic No incentive, no employee, friend, instrumental No incentive, employee, acquaintance, instrumental No incentive, no employee, acquaintance, symbolic No incentive, no employee, acquaintance, instrumental Incentive, employee, friend, symbolic Incentive, employee, friend, instrumental Incentive, no employee, friend, symbolic Incentive, employee, acquaintance, symbolic Incentive, no employee, friend, instrumental Incentive, employee, acquaintance, instrumental Incentive, no employee, acquaintance, symbolic Incentive, no employee, acquaintance, instrumental

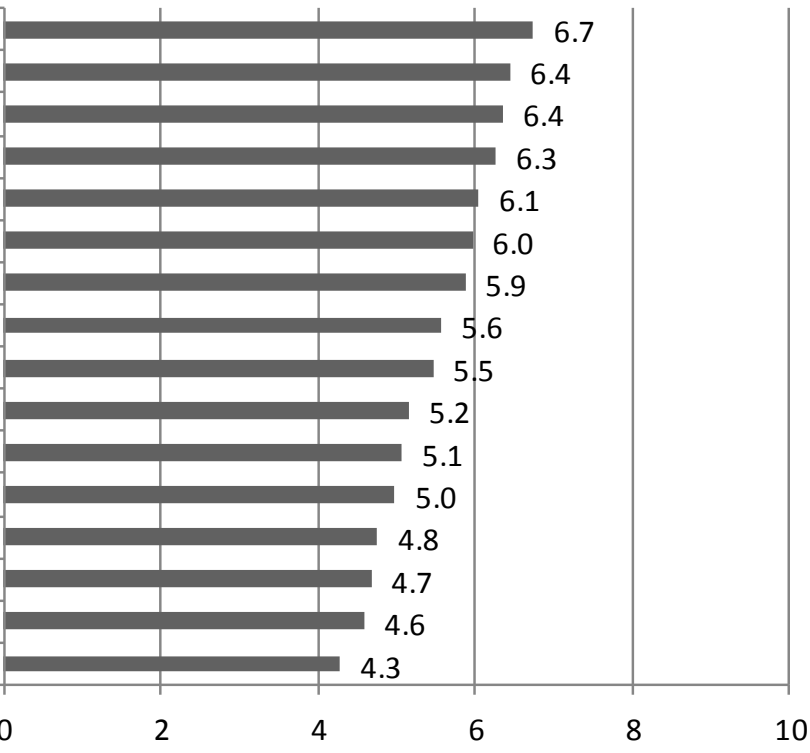

Expected organizational attractiveness

Figure 2. Expected organizational attractiveness as a function of significant word-of-mouth characteristics, in descending order (Study 2). 


\section{Appendix}

\section{Stimulus Example}

Below, a stimulus example is shown (translated from Dutch), corresponding to the high levels of all factors (see Table 1).

Evelien, a good friend of yours, sends you the following email:

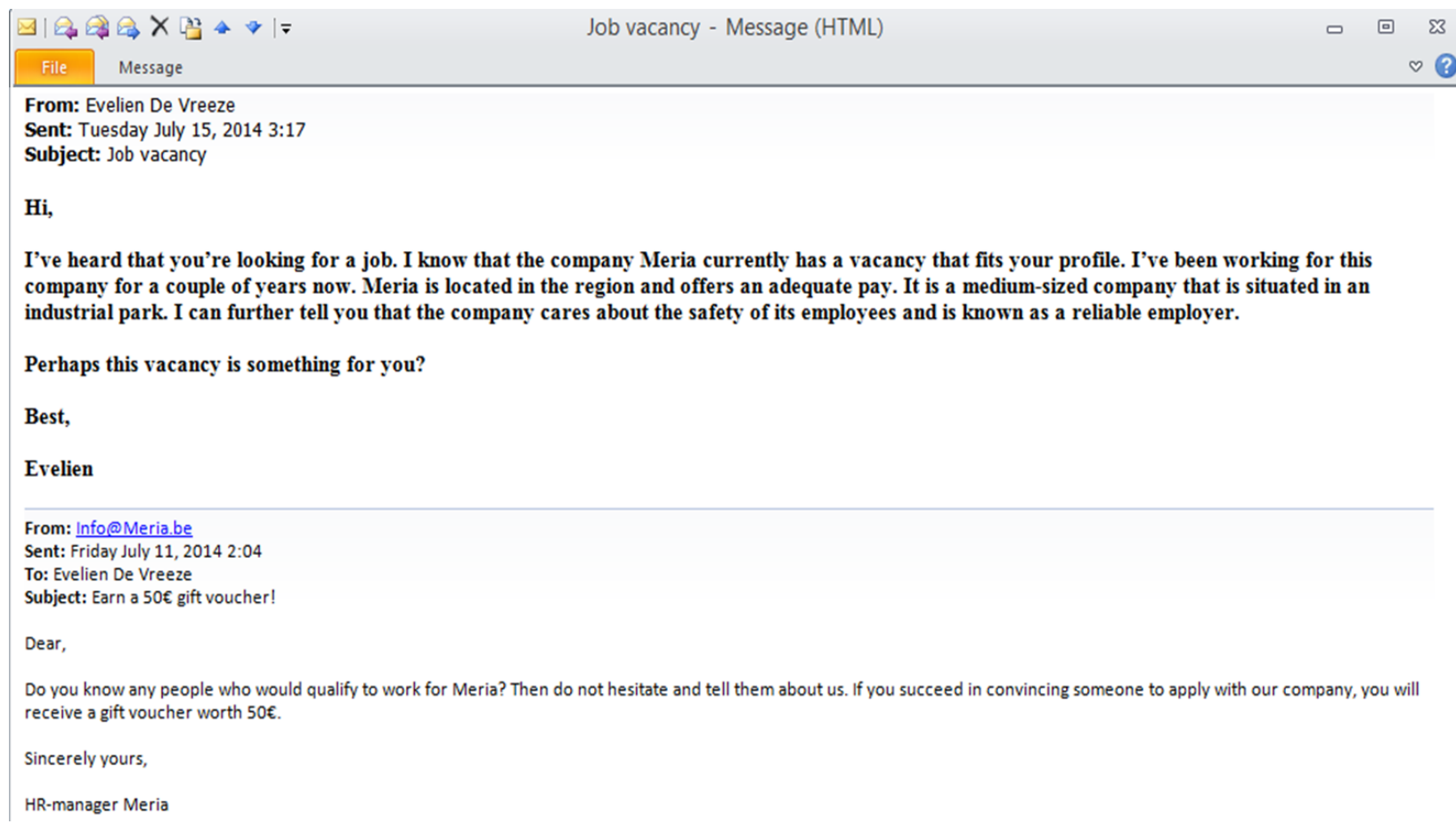

